\title{
METHODS OF STAKEHOLDER PRIORITISATION IN THE CONTEXT OF STAKEHOLDER MANAGEMENT
}

\author{
Aleksey MINTS ${ }^{1}$, Evelina KAMYSHNYKOVA ${ }^{2 *}$ \\ ${ }^{I}$ Department of Finance and Banking, Faculty of Economics, Pryazovskyi State Technical University, \\ Universytets'ka 7, 87500, Mariupol, Ukraine \\ ${ }^{2}$ Department of Economics of an Enterprise, Faculty of Economics, Pryazovskyi State Technical University, \\ Universytets'ka 7, 87500, Mariupol, Ukraine \\ ${ }^{*}$ E-mail: kamyshnykova_e_v@pstu.edu
}

\begin{abstract}
Purpose - the purpose of this paper is to propose a method for integral assessing the priority level of specific stakeholders in the model of stakeholder management.

Research methodology - the paper develops ideas of matrix approach to assessing the priority level of individual stakeholders and proposes a method for obtaining more accurate integral assessment based on analysis of a set of indicators, taking into account factors of subjective estimates.
\end{abstract}

Findings - the integral assessment of the priority level of specific external stakeholders improves estimates' accuracy and provides a practical framework for the development of successful corporate social responsibility strategies. It has been substantiated by the application of the proposed method for prioritising suppliers of a large Ukranian metallurgical company.

Research limitations - there are requirements for a linear or quasi-linear nature of the relationship between the numerical value of the stakeholder's priority index and its interpretation on a "better to worse" scale within the framework of the proposed method of evaluation.

Practical implications - integral assessments of stakeholder priority obtained from the results of the proposed method can be used as a tool for reasonable comparison, selection of strategic stakeholders and building programs for interaction with them.

Originality/Value - unlike most existing methods of stakeholder analysis representing a generic list of priority stakeholder groups the method proposed in the paper provides an integral assessment of priority level of specific stakeholders from the category of the immediate environment through a system of indicators, taking into account factors of subjectivity.

Keywords: prioritisation, stakeholder, opportunities, interest, expert assessment.

JEL Classification: M14.

Conference topic: Contemporary Organizations Development Management.

\section{Introduction}

Today, the company's success in the market and its development prospects depend largely on corporate social responsibility activities and their perception by various stakeholders. A stakeholder is "any group or individual who can affect or is affected by the achievement of the organisation's objectives" (Freeman, 2010).

Consulting firm EPG (2014) found that Fortune Global 500 companies spend US\$20 billion per year on corporate social responsibility activities. The extent and level of socially responsible business practices are constantly increasing. The growing awareness of consumers, supported by the global nature of communications are among the main factors of corporate social responsibility importance (Szymborska, Domanski, \& Adamczak, 2019). According to the Global RepTrak 100 study (2017) the quality of products and services $(20.5 \%)$, governance $(15.0 \%)$, corporate citizenship (14.4\%) are the key factors having the greatest impact on corporate reputation. This confirms the importance of corporate social responsibility governance in improving corporate image and building relationships with stakeholders. 
The effectiveness of corporate social responsibility is ensured through stakeholder management. Stakeholder management includes a set of methods for identification, prioritisation, planning and implementation of activities designed to engage and build positive interaction with stakeholders.

Aapaoja and Haapasalo (2014) emphasised the view that stakeholders cannot be managed as a homogenous group. Their different roles and responsibilities should be taken into account in stakeholder management to enhance value creation. According to Mabrouk, Sperandio, and Girard (2014) stakeholders from the same system not necessarily share the same concerns and mostly have different expectations and priorities. Simultaneous interaction with all identified groups of stakeholders with attempts to evenly meet their interests is a costly and ineffective step. To avoid this prioritisation process is used which includes splitting into groups of stakeholders and setting priorities among them according to various criteria. Prioritisation procedure allows the company to focus limited resources on the most important strategic directions in terms of meeting the key stakeholder groups.

Miscalculations associated with the erroneous allocation of certain groups of stakeholders as priorities for the company entail image and financial losses. Incorrectly chosen strategic direction of the company's development is the most dangerous consequence of missed or incorrectly performed procedures for prioritising stakeholders. When identifying the primary areas of strategic focus, interests and the degree of influence of strategic stakeholders groups should be taken into account. In this case, the company's resources and attention will not be "sprayed" on individuals with less priority influence, and conflicts with really important stakeholders will be prevented. Therefore, the problem of developing methods for conducting stakeholder prioritisation is very important. Despite of the availability of a wide range of methods for mapping stakeholder groups, there is a lack of methodological approaches for prioritising specific stakeholders.

The purpose of this paper is to propose a method for integral assessing the priority level of specific stakeholders in the model of stakeholder management. With this intention, the paper is structured as follows. In Section 1 we provide a theoretical framework of stakeholder mapping in the process of stakeholder prioritisation. Two-dimensional "power-opportunity" matrix is proposed as a tool for assessing the priority of interaction with stakeholder groups. In Section 2 we develop a method for assessing the priority level of specific external stakeholders from the category of the immediate environment through a designed system of indicators. In Section 3 practical application of the proposed method for a large Ukrainian metal company is given. In Section 4 benefits of the proposed method of integral assessment are substantiated. Finally, in conclusions, we discuss our findings and develop propositions for future research.

\section{Stakeholder mapping}

According to Bourne's methodology of managing relationships with stakeholders (2012) Stakeholder Circle involves identification, prioritisation, visualisation, engagement, and monitoring of stakeholder aspects.

In the model of effective management of stakeholder relationships interaction with stakeholders begins with the procedure for their identification. This stage includes the formation of a common list of all parties directly or indirectly concerned in the company's activities. Stakeholders' classification at different classification criteria (external and internal, primary and secondary, and so on), identification of their expectations and interests are also this stage's objectives.

The process of stakeholder prioritisation starts with stakeholder mapping which means visualising relationships to objectives and other stakeholders (Business for Social Responsibility, 2011). Different authors highlighted a variety of approaches in their studies to map the stakeholders.

According to Mitchell's theory (Mitchell, Agle, \& Wood, 1997), the relationship between stakeholders and the company must be evaluated from the standpoint of such attributes presented:

1. Power characterises the relationship between social players, in which one player causes the other one to do something that he would not have done. There are coercive (force or threat), practical (material or financial resources) or normative (symbolic influences) bases to exercise power.

2. Legitimacy means a generalised assumption that the actions of the entity are desirable, proper, or appropriate within some socially constructed system of norms, values, beliefs, definitions. There are the individual, organisational and social levels of legitimacy.

3. Urgency determines the extent to which interested parties require immediate attention from management.

The Mitchell model provides a practical tool for assessing the priority of interaction with stakeholder groups. Stakeholders are checked based on the possession of specified attributes. As a result of the evaluation, stakeholders are divided into classes of significance. Depending on possession and combination of attributes, seven stakeholder classes are distinguished.

Low salient classes termed "latent" are identified by possession of the only one stakeholder attribute. Company's management should take no actions concerning interest groups from "latent" class due to lack of time and other resources. The combination of two attributes describes stakeholders from the group of "expecting something" players. More active position and degree of influence of "expecting" interested groups force management to raise the level of interaction with these classes of stakeholders. Getting the appropriate missing attribute transfers stakeholders 
to the class of "definitive" ones, that is, those that have a complete set of attributes. Accordingly, such interested groups and their representatives are key players in terms of building relationships with them.

Westrenius and Barnes (2015) examined the stakeholder prioritisation in Australian small business using the Mitchell et al. (1997) power, legitimacy and urgency framework. Looser and Wehrmeyer (2015) conducted the analysis of the current state of corporate social responsibility in Switzerland, using Mitchell's stakeholder map methodology, showing power, urgency, legitimacy and concerns of different actors. Lusticky, Zaunmüllerová, Váchová and Kadeř́aková (2015) used importance, proximity and urgency as three key attributes to calculate the Stakeholder Index for the specific condition of the tourism sector in Chech regions. Cameron, Seher, and Crawley (2011) developed an approach to estimating stakeholders' needs and their relative importance to others in the network as characteristics for stakeholder ranking. In Imperial College London's stakeholder analysis grid (2017) influence and interest are considered as two main terms of determining stakeholder position on a graph. Business for Social Responsibility (2011) has developed a list of criteria for stakeholder mapping including contribution (value), legitimacy, willingness to engage, influence and necessity of involvement. Plotitsina and Boyarov (2011) also consider many criteria to be important for prioritising strategic groups of stakeholders. The basic criteria for cooperation with the company include long term partnership, joint actions; inability to fix the relationship only through contract.

Matrix with two or three dimensions is often used as a tool for visual representing stakeholder priority. Mendelow's matrix (Mendelow 1991) is one of the basic methods for mapping stakeholders. The allocation of power and interest as two key characteristics of stakeholders are provided in it. Stakeholders' power is due to their ability to influence organisational strategies or resources, while their willingness to do this determines interest. According to this model stakeholders with maximum power and interest in relation to the corporation are the priority ones.

The category characterising stakeholders determines the required degree of interaction with them. Key players who have both high power and high level of interest should be completely satisfied by the management's efforts. Stakeholders with high power, but low interest are in "keep satisfied" category. It is necessary to pay enough attention to support satisfaction of these stakeholders, not overloading them with the messages. Low power with high interest characterises "keep informed" stakeholders. It is advisable to adequately inform and support these social groups so that they can identify areas that can be improved or ignored. Stakeholders with low power and low interest require minimum effort. Regular monitoring to track changes in the level of interest or power is enough for this category of stakeholders.

Freeman (2010) has also proposed two-dimensional grid categorising stakeholders in terms of power and interest. As a step of stakeholder management stakeholder mapping contributes to balancing stakeholder interests and organisational processes.

Based on the "power-interest" characteristics, Eden and Ackerman (2013) proposed a modified matrix, according to which stakeholders were classified in the following way: players who have direct interest and high power, context setters who have considerable power but low interest, subjects having significant interest but low power, and the crowd including stakeholders with low interest and power. Just as in the Mendelow's matrix, players in Eden and Ackerman matrix are recognised as the priority category of stakeholders, which has the most powerful potential for collaboration.

In Martirosyan and Vashakmadze paper (2014), a modified Mendelow's matrix was proposed with new axis reflecting the stakeholders' attitude to M\&A deal (positive or negative). Using this tool allows management to focus on "right stakeholders" that are important for creating synergy. Synergy creators, unlike destroyers, are characterised by a positive attitude to the deal and the highest level of influence on it. Application of the Martirosyan's matrix is limited because of its focus on the identification of priority stakeholders with the greatest impact on the M\&A deal.

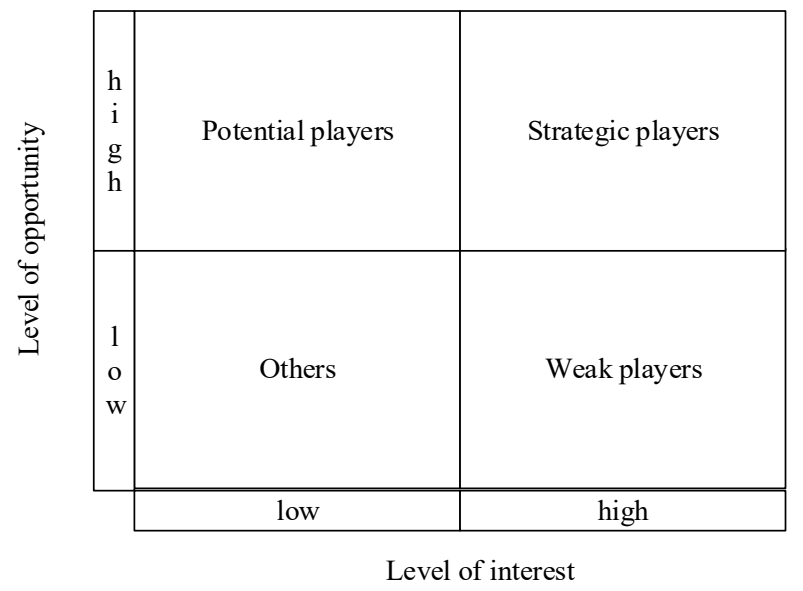

Figure 1. Matrix of stakeholder prioritisation (created by authors) 
Although "power-interest" grid is a good tool for stakeholder prioritisation, it still needs improvement. In Eden and Ackerman's paper (2013) the term "power" is left undefined since the stakeholder literature gives no consistent or precise definition of power.

To assess the priority level of stakeholder groups, we propose to apply a matrix with two axes (attributes). Unlike two key stakeholder characteristics from Mendelow's matrix (power versus interest), we consider it appropriate to evaluate the attributes of opportunities versus interest (Figure 1). Compared with the concept of "power", "opportunities" is a broader economic category that reflects the internal forces, resources, capabilities of a subject. Opportunities are an integral characteristic of the level of cooperation potential with a particular stakeholder group. Interest reflects the level of interest for realising this potential.

The application of this matrix allows classifying stakeholders into four groups. The following strategic actions should be applied to each one:

1. Strategic players with the highest level of opportunity and interest are the category of stakeholders with top priority. Management should build mutually beneficial relationships with them. Harmonising company's interests with interests of this group of entities lead to ensuring its long-term competitiveness, the formation and implementation of relational potential.

2. Potential players have a high level of opportunity with a low level of interest. The strategic objective of corporate management is to maximise awareness of this category of players to enhance their interest, loyalty to the company and release the potential of interaction with them.

3. Weak players are characterised by a high level of interest and a low level of opportunity. Such stakeholders are interested in interacting with a socially responsible corporate entity, but because of their small potential total possibilities of interacting with them are limited. It is appropriate to maintain feedback from this group of stakeholders for management on a rationally limited resource base.

4. Other stakeholder groups are characterised by a combination of the low level of opportunities and interest. Collaboration programs with this group of stakeholders are the least profitable for the company.

We propose to analyse of the priority level of all stakeholder groups interacting with the company with further mapping using matrix "opportunities-interest" by expert evaluation method. The scale for assessing the presence of an attribute has an interval of values $[0 ; 1]$, where 0 means the complete absence of a feature in a group being the object of analysis, and 1 is the maximum expression of this attribute, respectively. Intermediate assessments characterising salience of features are between the extreme values of opportunity and interest.

After composing a generic list of stakeholders, their further disaggregation is required to achieve specificity in managing stakeholders.

\section{Method of integral assessment of the specific stakeholder's priority level}

A lack of previous research of prioritising specific stakeholders as a step of stakeholder management suggested a need for the development of such methodology.

Majumdar, Md. S. Rahman and Md. R. Rahman (2014) designed an approach which is based on "fuzzy logic" for prioritising selected stakeholders in the software development sphere. The research has a limitation of application. The framework can be used for pointing out the best candidates who are eligible to be involved in the requirement engineering process.

Bourne (2015) proposed the method to assess the relative importance of stakeholders by considering such factors as power, proximity and urgency. Based on these three factors an "Index Value" was calculated that varied 1 (low) to 5 (high). The author herself (Bourne, 2015) emphasised a degree of subjectivity in applying this method of prioritisation.

It is difficult to avoid subjectivity connected with the use of expert evaluation methods in the process of stakeholder prioritisation. To clarify the assessments and further prioritise individual subjects of influence, a method for assessing the priority level of external stakeholders from the category of the immediate environment is proposed. As the analysis showed (Ramu \& Kulkarni, 2018; Westrenius \& Barnes, 2015), stakeholders in the immediate environment, including consumers, suppliers, competitors (partners) are among the key stakeholder groups for all types of companies.

The integral assessment of opportunities and interest as attributive characteristics for prioritising stakeholders through a system of indicators is the core of the proposed approach (Table 1).

The system of integral assessment of the priority level of stakeholders from the category of the immediate environment involves the following steps:

1. Calculation of single indicators characterising the level of stakeholder opportunities.

2. Converting calculated values of single indicators from the "level of opportunity" attribute to normalised ones.

3. Calculation of single indicators characterising the level of stakeholder interest.

4. Converting calculated values of single indicators from the "level of interest" attribute to normalised ones.

5. Formation of integral indexes characterising the stakeholder's level of opportunities and interest. 
Table 1. Integral assessment of the priority level of stakeholders from the category of the immediate environment (created by authors)

\begin{tabular}{|c|c|c|c|c|}
\hline \multirow{2}{*}{ Indicators } & \multicolumn{2}{|c|}{ Stakeholder 1} & \multicolumn{2}{|c|}{ Stakeholder $\mathrm{n}$} \\
\hline & Calculated value & Normalised value & Calculated value & Normalised value \\
\hline \multicolumn{5}{|l|}{ Level of opportunity } \\
\hline \multicolumn{5}{|l|}{ 1. Share in the total value of assets } \\
\hline \multicolumn{5}{|l|}{ 2. Share in the total sales } \\
\hline \multicolumn{5}{|l|}{ 3. Share in the total brand value } \\
\hline \multicolumn{5}{|l|}{ 4. The growth rate of assets } \\
\hline \multicolumn{5}{|l|}{ 5. The growth rate of sales } \\
\hline \multicolumn{5}{|l|}{ 6. The growth rate of brand value } \\
\hline \multicolumn{5}{|l|}{ 7. Operating efficiency level } \\
\hline \multicolumn{5}{|l|}{$\begin{array}{l}\text { 8. Market share of a particular product } \\
\text { (service) }\end{array}$} \\
\hline \multicolumn{5}{|l|}{ Integral index } \\
\hline \multicolumn{5}{|l|}{ Level of interest } \\
\hline \multicolumn{5}{|l|}{$\begin{array}{l}\text { 1. Proximity of location (district / city } \\
\text { / region / state / other countries) }\end{array}$} \\
\hline \multicolumn{5}{|l|}{$\begin{array}{l}\text { 2. Interaction time (single transaction } \\
\text { / long-term cooperation) }\end{array}$} \\
\hline \multicolumn{5}{|l|}{$\begin{array}{l}\text { 3. Degree of dependence (full / partial } \\
\text { / weak) }\end{array}$} \\
\hline Integral index & & & & \\
\hline
\end{tabular}

More detailed consideration of these steps is presented below.

\subsection{Calculation of single indicators characterising the level of stakeholder opportunities}

The following symbols are introduced: $\mathrm{S}=[1 . . \mathrm{s}]-$ set of stakeholders; $M=\left[m_{s}^{j m}\right]-$ set of indicators of the stakeholder opportunities, where $s=1 . . s_{\max }$ - stakeholder's number, $j m$ - indicator's number. Indicators characterising the level of stakeholder opportunities can be divided into several groups $M 1, M 2, M 3, \ldots \in M$.

The first group (M1) includes indicators determining the relative strength of the stakeholder. These are the share in the total value of assets, sales and brand value of all analysed stakeholders. Indicators from the $M 1$ group are defined as:

$$
m 1_{s}^{j m}=\frac{m_{s}^{j m}}{\sum_{s} m_{s}^{j m}}, \quad m^{j m} \in M 1
$$

The group M2 includes indicators determining the rate of stakeholder's development. These are the growth rate of assets, sales and brand value. Indicators from the $M 2$ group are defined as:

$$
m 2_{s}^{j m}(t)=\frac{m_{s}^{j m}(t)-m_{s}^{j m}(t-1)}{m_{s}^{j m}(t-1)}, \quad m^{j m} \in M 2,
$$

where $t$ is a period for which calculations are carried out. If financial statements are an information base, then $(t)$ means the current period, and $(t-1)$ is the basic one.

Other indicators are used without further processing and classified into $M 3$ group. These include operating efficiency level and market share of a particular product (service). Indicators from the $M 3$ group are defined as

$$
m 3_{s}^{j m}=m_{s}^{j m}, \quad m^{j m} \in M 3 .
$$

Since each indicator is included in only one group, then $M=M 1+M 2+M 3$. 


\subsection{Converting calculated values of single indicators from the "level of opportunity" attribute to normalised ones}

Normalisation of indicators is necessary to ensure their comparability during further analysis. The purpose of normalisation is to ensure the distribution of all possible values of indicators within the same interval. Let us denote the set of normalised indicators of the level of opportunity as $\hat{M}$.

$$
\hat{M}=\hat{M} 1+\hat{M} 2+\hat{M} 3 .
$$

Indicators of $M 1$ set in terms of calculation do not go beyond the interval [0;1], therefore $\hat{M}=M 1$. For indicators of groups $M 2$ and $M 3$, it is advisable to apply normalisation since their values may go beyond the interval [ -1 ; 1]. There are a number of methods for normalisation, in particular, minimax, normalisation by standard deviation, adaptive etc. In this case, the normalisation method must meet requirements such as:

- Consider significant parameters which values vary in a small range compared to others;

- The resulting (normalised) values should be in a limited range.

Therefore, to convert the calculated values of single indicators characterising the level of stakeholder opportunities to normalised estimates in the interval $[0 ; 1]$, or $[-1 ; 1]$ sigmoid function is suggested to be used. The sigmoid function (sigmoid) is a continuously differentiable monotonically increasing nonlinear S-shaped membership function, which is used to "smooth out" the values of variables. The sigmoid function is often used for "compressing". It allows narrowing the range of variation of the measured value so that the output values belong to a certain finite range for any values of the input data. The logistic sigmoid function asymptotically approaches the value 0 when the argument tends to minus infinity and 1 when the argument tends to plus infinity (Goodfellow, Bengio, \& Courville, 2016). The equation represents the sigmoid function:

$$
f(x)=\frac{1}{1+e^{-(x)}} .
$$

In addition to the logistics functions root function can be used for normalisation, which is:

$$
f(x)=\frac{x}{\sqrt{1+x^{2}}} .
$$

Compared to logistic sigmoid, changes in parameters in a wider range of values are taken into account more adequately through root function. Furthermore, its use does not require additional mathematical operations for normalisation in the interval $[-1,1]$. Since indicators in $M 2$ and $M 3$ groups can have negative values, the root function is more convenient to use. Thus, the normalised values of indicators of stakeholder opportunity level are determined as follows:

$$
\hat{m}_{s}^{j m}=\frac{m_{s}^{j m}}{\sqrt{1+m_{s}^{j m 2}}}, \quad m_{s}^{j m} \in M 2, M 3 .
$$

\subsection{Calculation of single indicators characterising the level of stakeholder interest}

A lack of precise methods for evaluating is a peculiarity of indicators characterising the stakeholder interest level. In such cases, it is appropriate to use evaluation methods based on expert judgment. Despite the widespread use of expert evaluation methods, they have some shortcomings. The high cost and long duration of the examination, the need to manage the organisational mechanism of expertise, as well as the impact of individual subjective factors of experts on the results of the evaluation are among them. It is the subjective aspect of expert evaluation should be recognised as the major disadvantage of this method.

Subjective factors include the degree of expert's interest in the results of use of the examination's final data, his competence in the analysed subject area, the depth of expertise, the number of experts involved in evaluation, the level of expert's education and his awareness of characteristics of analysed subject area, his intuition. The problem of minimizing the subjectivity of expert information is not new, and currently, there are different approaches to its solution. Hal'chyns'kyi, Heets', Kinakh and Semynozhenko (2002) proposed to assess the experts' objectivity, that is, to check controversy of interviewed experts, using the following rules (with the application of a 10-point scale of assessment):

$$
\begin{gathered}
\max \left|O_{a}-O_{b}\right|<5, \\
\sum\left|O_{a}-O_{b}\right| / n<2.5 .
\end{gathered}
$$


Rule (8) indicates that the maximum allowable difference between the two estimates of experts (in absolute value) for each parameter should be less than 5 points. Rule (9) evaluates the consistency of experts on average for all factors. However, it is not a universal approach, because rules (8) and (9) can be followed in the situation when all experts gave a distorted assessment. Also, the choice of boundaries at values 5 and 2.5 in these rules is not substantiated.

Lepa (2006) gave a more complex and effective approach to minimizing the subjectivity of expert evaluation. This approach is based on the hypothesis that the overall error of the $i$-th expert consists of two parts - interest errors $\left(R_{i}\right)$ and incompetence errors. The author proved that in a relatively small quantity of incompetence errors of $i$-expert, it is possible to adjust his estimates. The obtained estimate differs from the true value by no more than $\left(\varepsilon_{i}\right)$, that is, the value of incompetence. However, this approach is also not free from shortcomings. The need for a large database of background expert evaluation for each of the experts is the main one.

\subsection{Converting calculated values of single indicators from the "level of interest" attribute to normalised ones}

In most cases, getting expert estimates, their regulation and elimination of subjective factors in evaluating indicators characterising the level of stakeholder interest can be represented in the following algorithm:

1. Formation of forms for evaluating indicators. Also, each one should be considered as an integrated indicator determined by the evaluation of a set of factors. Thus, the factors that determine the "proximity of location" may include such as geographical proximity; administrative proximity (location within a city, region, etc.); corporate proximity (areas of activity); time needed to get to stakeholder etc. It can be assumed that each indicator of the stakeholder interest consists of a set of factors: $c_{s}^{j c}=\left[f_{c}^{j c}\right]$

2. Examination and preliminary processing of results. Let us introduce the following symbols: $\mathrm{C}=\left[c_{s}^{j c}\right]-$ set of indicators of stakeholder interest, where $s=1 . . s m a x-$ stakeholder number, $j c$ - index number; $p$ - expert; $f$ - factor; $r^{p}\left(c_{s}^{j c}[f]\right)-p$-th expert's estimate for $f$-th factor of indicator of stakeholder interest $c_{s}^{j c}$; $r \max _{f}^{j c}$ - high estimate of $f$-th factor of indicator $j c ; R N_{j c}$ - normalisation parameter which corresponds to high estimate of normalised scale by the indicator $j c$. Then, the normalised rating from the $p$-th expert of $j c$ indicator of stakeholder interest $s$ can be defined as:

$$
n c_{s}^{j c}[p]=R N_{j c} \cdot \frac{\sum_{f} r^{p}\left(c_{s}^{j c}[f]\right)}{\sum_{f} r \max _{f}^{j c}} .
$$

3. Reducing estimates' subjectivity. If the application of approach proposed in (Lepa, 2006) is impossible due to a lack of data, statistical methods should be used based on excluding extremes of data. So, from the set of estimates of indicator $w$ made by different experts the maximum, $\max \left(R_{w i}\right)$ and the $\operatorname{minimum}, \min \left(R_{w i}\right)$ estimates should be removed. Subsequently, the consistency of expert assessments is checked through compliance with the conditions (8) and (9). It should be mentioned that the threshold values in these mathematical expressions can be used unchanged only with $R N_{w}=10$. In other cases, they should be changed proportionally. If conditions (8) and (9) are not met, the expert evaluation procedure should be considered unsuccessful. This can be caused either by an unsuccessful implementation of the first phase or by unsuccessful selection of expert groups.

After analysing and eliminating failure factors, the evaluation procedure should be repeated.

4. Averaging the results of expert evaluations. At this stage, the average rating for each indicator $j c$ of stakeholder's interest $s$ is normalised in the interval $[0 ; 1]$.

$$
\bar{c}_{s}^{j c}=\frac{\sum_{p} n c_{s}^{j c}[p]}{|P| \cdot R N_{j c}},
$$

where $|P|$ - the number of expert estimates to be averaged.

\subsection{Formation of integral indexes characterising the stakeholder's level of opportunities and interest}

Performing steps 1 to 4 allows us to obtain normalised estimates of stakeholder's level of opportunities and interest. Formation of an integral index of the stakeholder's priority can be done in two ways: 
1. If consider all calculated single indicators to be equivalent to the influence on the stakeholder's priority, the integral index of $s$ stakeholder priority will look like:

$$
P I_{s}=\frac{\sum_{j m} \hat{m}_{s}^{j m}+\sum_{j c} \bar{c}_{s}^{j c}}{|M|+|C|},
$$

where $|M|,|C|$ - the power of sets $\mathrm{M}$ and $\mathrm{C}$, which is equal to the number of indicators of stakeholder opportunities and interest, respectively. The higher the integrated index, the higher the priority in interaction with $s$ stakeholder.

2. Expression (12) should be used at initial stages of implementation of management processes for interaction with stakeholders. However, as far as accumulation of actual information on the results of interactions grows, data on the inequivalent influence of single indicators of opportunity and interest on the final estimation of the stakeholder's priority may appear. In this case after clarifying the importance of indicators the following expression for calculating the priority can be used:

$$
P I_{S}=\frac{\sum_{j m} a^{j m} \cdot \hat{m}_{s}^{j m}+\sum_{j c} b^{j c} \cdot \bar{c}_{s}^{j c}}{|M|+|C|},
$$

where $a^{j m}$ and $b^{j c}$ are weights of indicators of stakeholder opportunities and interests, respectively. Basic values of weights are equal to 1 . With these values, the expression (13) is simplified to the expression (12). If it is necessary to increase the significance of the indicator $\mathrm{jm}$, or $\mathrm{jc}$, and its effect on the resulting estimate, we should increase the corresponding coefficient $a^{j m}$ or $b^{j c}$ and vice versa. The final coefficients $a^{j m}$ and $b^{j c}$ can be obtained only on the analysis of practical results of implementing of stakeholder management mechanisms. It should be noted that these coefficients can be different for different sectors of the economy. Expression (13) allows obtaining integral indexes of stakeholder priority on the basis of formal and expert evaluation. This enables to have a tool for a reasonable comparison of different stakeholders in the company's management system.

Lack of requirements for background data availability, relatively small costs of the evaluation process are benefits of the proposed method. Using calculated integral index makes it possible to specify the position of particular stakeholder from the category of consumers, suppliers or competitors on the scale of "opportunity-interest". Thus, in contrast to existing methods of prioritising stakeholder groups this method allows for in-depth evaluation of the priority of individual subjects in groups with further ranking based on the results.

\section{Practical application of the method of integral assessing specific stakeholder's priority level}

Let us consider the use of the proposed method of integral assessment of the specific stakeholder's priority level for a large metallurgical company. Ilyich Iron and Steel Works of Mariupol (MMKI, Ukraine) is chosen as the object of analysis. To verify the effectiveness of the proposed method for prioritising stakeholders, it is advisable to conduct a retrospective analysis based on data from 2009-2010 since that period was the most difficult for the company.

By the period under review, the process of consolidation and creation of vertically integrated mining and metals structures was completed in Ukrainian metallurgy. Vertical integration was set as a priority for Ilyich Iron and Steel Works of Mariupol later than at the other metallurgical companies. Therefore, this process could not be fully completed, and the company had to purchase raw materials from its competitors partially.

Leading suppliers of metallurgical raw materials of MMKI in 2009 (Ilyich Iron and Steel Works of Mariupol, 2010) belong to the groups of companies. Russian suppliers of iron ore concentrate and sintering ore (Lebedinsky GOK, Mikhailovsky GOK, Kovdorsky GOK, Stoilensky GOK) should be analysed as the whole structure too.

The companies or their groups can be considered as MMKI stakeholders. Initial data set for further research was formed from open data sources of their activities (Table 2).

Table 2 has some differences compared with the form of Table 1. These differences are due to the characteristics of the industry and companies under research. Thus, indicators related to the stakeholders' total value of assets and brand value were ignored, since they are not important for assessing the level of opportunity for mining companies.

Indicators "the growth rate of total sales" and "operating efficiency level" are described linguistically. The growth rate of total sales of Russian companies is relative only to the supply of their products in Ukraine. The volume of supplies began to decline in 2009 , due to the financial crisis and devaluation of the national currency. Similarly, these companies' market share is listed only in relation to the Ukranian market, while sales volumes are general. 
Table 2. Initial data for assessing the priority level of MMKI stakeholders (created by authors)

\begin{tabular}{|c|c|c|c|c|c|c|c|c|}
\hline \multirow[b]{2}{*}{ Suppliers } & \multicolumn{5}{|c|}{ Level of opportunity } & \multicolumn{3}{|c|}{ Level of interest } \\
\hline & 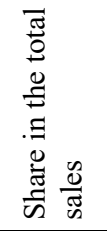 & 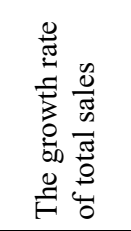 & 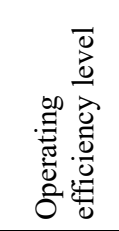 & 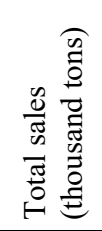 & 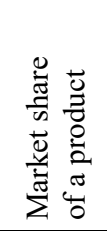 & 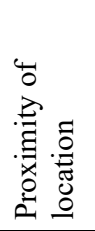 & 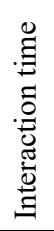 & 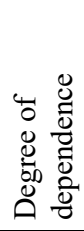 \\
\hline \multicolumn{9}{|l|}{ Iron ore concentrate } \\
\hline Metinvest Group (Ingulets GOK) & $70.8 \%$ & neutral & positive & 13728 & $30 \%$ & 5 & 10 & 9 \\
\hline Russian GOKs & $29.2 \%$ & negative & positive & 58379 & $3 \%$ & 2 & 10 & 5 \\
\hline \multicolumn{9}{|l|}{ Sintering ore } \\
\hline MMKI (GOK Ukrmechanobr) & $39.6 \%$ & positive & neutral & 614 & $6 \%$ & 5 & 10 & 3 \\
\hline Krivoy Rog's Iron Ore Combine & $22.4 \%$ & neutral & positive & 4650 & $45 \%$ & 5 & 10 & 3 \\
\hline Evraz Group (GOK Sukha Balka) & $18.0 \%$ & neutral & positive & 2950 & $29 \%$ & 5 & 10 & 3 \\
\hline Russian GOKs (Stoilensky) & $16.8 \%$ & negative & positive & 15636 & $7 \%$ & 2 & 10 & 5 \\
\hline \multicolumn{9}{|l|}{ Blast furnace coke } \\
\hline $\begin{array}{l}\text { MMKI (Yasinovsky Coking } \\
\text { Plant) }\end{array}$ & $46.1 \%$ & positive & neutral & 1375 & $7.30 \%$ & 6 & 10 & 5 \\
\hline $\begin{array}{l}\text { Metinvest Group (Avdiivka Coke } \\
\text { Plant) }\end{array}$ & $26.9 \%$ & neutral & positive & 4520 & $24 \%$ & 6 & 10 & 7 \\
\hline $\begin{array}{l}\text { Evraz Dneprodzerzhinsk Coke } \\
\text { and Chemical Plant }\end{array}$ & $13.3 \%$ & neutral & positive & 557 & $3 \%$ & 4 & 10 & 5 \\
\hline Donetsksteel & $6.5 \%$ & negative & positive & 1243 & $6.90 \%$ & 7 & 10 & 5 \\
\hline
\end{tabular}

Summary table obtained after normalisation procedures and integral assessment of the level of stakeholder opportunity and interest is as follows (Table 3).

Table 3. Calculation of integral index of the priority level of MMKI stakeholders (created by authors)

\begin{tabular}{|c|c|c|c|c|c|c|c|c|c|c|}
\hline \multirow[b]{2}{*}{ Suppliers } & \multicolumn{6}{|c|}{ Level of opportunity } & \multicolumn{4}{|c|}{ Level of interest } \\
\hline & 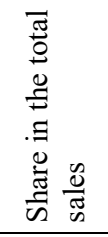 & 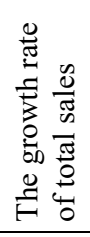 & 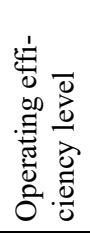 & 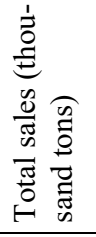 & 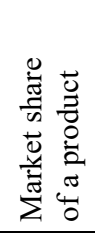 & 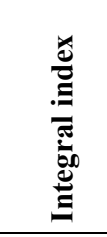 & 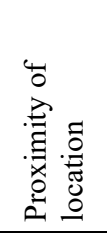 & 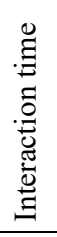 & 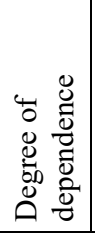 & 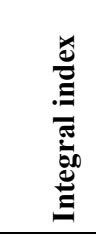 \\
\hline \multicolumn{11}{|l|}{ Iron ore concentrate } \\
\hline Metinvest Group (Ingulets GOK) & $70.8 \%$ & 0 & 1 & 0.19 & $30 \%$ & $44.0 \%$ & $71.4 \%$ & 1 & 1 & $90.5 \%$ \\
\hline Russian GOKs & $29.2 \%$ & -1 & 1 & 0.81 & $3 \%$ & $22.6 \%$ & 0.29 & 1 & 0.56 & $61.4 \%$ \\
\hline \multicolumn{11}{|l|}{ Sintering ore } \\
\hline MMKI (GOK Ukrmechanobr) & $39.6 \%$ & 1 & 0 & 0.03 & $6 \%$ & $29.6 \%$ & 0.71 & 1 & 0.33 & $68.3 \%$ \\
\hline Krivoy Rog's Iron Ore Combine & $22.4 \%$ & 0 & 1 & 0.19 & $45 \%$ & $37.4 \%$ & 0.71 & 1 & 0.33 & $68.3 \%$ \\
\hline Evraz Group (GOK Sukha Balka) & $18.0 \%$ & 0 & 1 & 0.12 & $29 \%$ & $31.9 \%$ & 0.71 & 1 & 0.33 & $68.3 \%$ \\
\hline Russian GOKs (Stoilensky) & $16.8 \%$ & -1 & 1 & 0.66 & $7 \%$ & $17.9 \%$ & 0.29 & 1 & 0.56 & $61.4 \%$ \\
\hline \multicolumn{11}{|l|}{ Blast furnace coke } \\
\hline MMKI (Yasinovsky Coking Plant) & $46.1 \%$ & 1 & 0 & 0.18 & $7.30 \%$ & $34.2 \%$ & 0.86 & 1 & 0.56 & $80.4 \%$ \\
\hline $\begin{array}{l}\text { Metinvest Group (Avdiivka Coke } \\
\text { Plant) }\end{array}$ & $26.9 \%$ & 0 & 1 & 0.59 & $24 \%$ & $41.9 \%$ & 0.86 & 1 & 0.78 & $87.8 \%$ \\
\hline $\begin{array}{l}\text { Evraz Dneprodzerzhinsk Coke and } \\
\text { Chemical Plant }\end{array}$ & $13.3 \%$ & 0 & 1 & 0.07 & $3 \%$ & $24.7 \%$ & 0.57 & 1 & 0.56 & $70.9 \%$ \\
\hline Donetsksteel & $6.5 \%$ & -1 & 1 & 0.16 & $6.90 \%$ & $5.9 \%$ & 1 & 1 & 0.56 & $85.2 \%$ \\
\hline
\end{tabular}


As noted above, mining and metals companies of Ukraine are combined into a relatively small number of large corporations at this time. Therefore, it is advisable to summarise the integral estimates obtained in Table 3 to determine the priority level of interaction with such stakeholder groups (Table 4).

Table 4. Integral assessment of the priority level of MMKI stakeholder groups (created by authors)

\begin{tabular}{|l|c|c|c|}
\hline \multirow{2}{*}{ Stakeholder groups } & \multicolumn{2}{|c|}{ Integral index } \\
\cline { 2 - 4 } & Level of opportunity & Level of interest & Total \\
\hline Metinvest & 0,86 & 1,78 & 2,64 \\
\hline Evraz & 0,57 & 1,39 & 1,96 \\
\hline MMKI & 0,64 & 1,49 & 2,13 \\
\hline Russian companies & 0,41 & 1,23 & 1,63 \\
\hline Other & 0,43 & 1,53 & 1,97 \\
\hline
\end{tabular}

The results of analysis by all types of indexes (Table 4) showed that Metinvest Group had been the most important stakeholder for the company under investigation. Priority of this Group's companies was even more than those included in MMKI group. Also, it should be noted that in 2010, that is, one year after the time for which the analysis was conducted, MMKI group was acquired by Metinvest Holding. This development fully confirms the results obtained and allows us to conclude about the practical significance of the proposed method of assessment.

\section{Benefits of stakeholder prioritisation in the stakeholder management system}

Stages of stakeholder prioritisation based on the proposed method of integral assessment of the stakeholder priority level are presented in Figure 2.

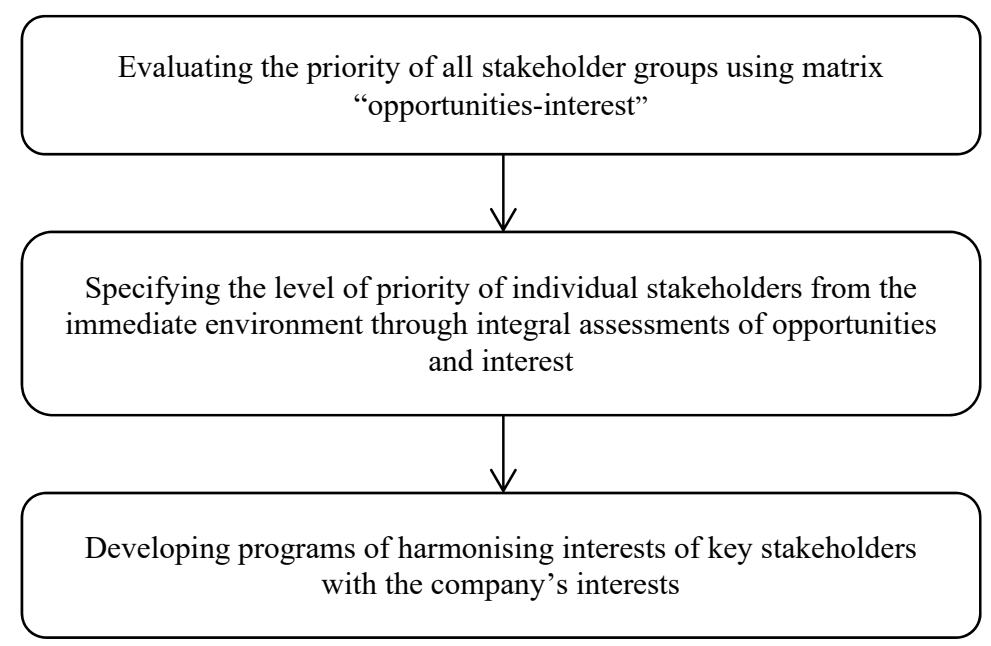

Figure 2. Stages of stakeholder prioritisation in the context of stakeholder management (created by authors)

The process of prioritising stakeholders should be cyclically repeated and the results updated due to changes in external and internal company's environment. The process of stakeholder prioritisation should be integrated into the overall stakeholder management process. Prioritisation of stakeholders, taking into account their needs and harmonising their interests with the company's interests as stages of stakeholder management allow:

- To achieve the strategic goals of the company most optimally with the support of key stakeholder groups;

- To choose ways of the most effective use of the company's resources;

- To reduce the risk level caused by the conflict of stakeholders' interests (Kimmich, Janetschek, MeyerOhlendorf, et al. 2012);

- To develop programs of interaction with stakeholders on the basis of the personalisation factor;

- To maintain the proper level of awareness in groups the most interested in the company's processes and results, and receive feedback from them;

- To build relationships with strategic stakeholders based on trust;

- To identify new strategic opportunities through information about products and business processes received from "strategic" groups of stakeholders and their representatives. 


\section{Conclusions}

In the system of CSR strategic management, the issue of stakeholder prioritisation plays an important role, since it is one of stakeholder management stages. Prioritisation is aimed at highlighting key stakeholder groups in the total stakeholder community according to various criteria in order to meet their needs and build a harmonious relationship with them. A list of criteria for stakeholder mapping includes power, influence, interest, attitude, legitimacy, urgency and others. The process of stakeholder prioritisation starts with stakeholder mapping on the basis of the matrix approach. To assess the priority level of stakeholder groups it has been proposed to apply the modified matrix with the attributes of opportunities versus interest. This matrix allows classifying stakeholders into four groups and specifying strategic actions that should be applied to each one.

The method of assessing the priority level of external stakeholders from the category of the immediate environment has been proposed for further prioritising individual subjects of influence. It provides the integral assessment of opportunities and interest as attributive characteristics for prioritising stakeholders through a system of indicators taking into account factors of subjectivity. The proposed method has been used for integral assessing the priority level of suppliers of a large Ukranian metallurgical company, and it has proved its practical applicability. Requirements for linear or quasi-linear nature of the relationship between indicator's numerical value and its interpretation on "worse-better" scale must be fulfilled for the indicators of the stakeholder's priority level within the framework of the proposed method of evaluation. Overcoming this disadvantage forms basis for further research.

\section{Disclosure statement}

We have no competing financial, professional, or personal interests from other parties.

\section{References}

Aapaoja, A., \& Haapasalo, H. (2014). A framework for stakeholder identification and classification in construction projects. Open Journal of Business and Management, 2, 43-55. https://doi.org/10.4236/ojbm.2014.21007

Bourne, L. (2012). Stakeholder relationship management: a maturity model for organisational implementation. Gower Publishing, Ltd.

Bourne, L. (2015). Stakeholder identification and prioritisation. Series on stakeholder engagement. PM World Journal, 4(5), 1-6.

Cameron, B. G., Seher, T., \& Crawley, E. F. (2011). Goals for space exploration based on stakeholder value network considerations. Acta Astronautica, 68(11-12), 2088-97. https://doi.org/10.1016/j.actaastro.2010.11.003

Eden, C., \& Ackermann, F. (2013). Making strategy: The journey of strategic management. London: SAGE.

EPG. (2015). Business backs education report. Retrieved from http://www.unesco.org/education/BBE-EPG-Report2015.pdf

Freeman, R. E. (2010). Strategic management: A stakeholder approach. Cambridge, MA: University Press. https://doi.org/10.1017/CBO9781139192675

Global CSR RepTrak 100. (2017). Retrieved from https://www.reputationinstitute.com/research/2017-global-csr-reptrak

Goodfellow, I. J., Bengio, Y., \& Courville, A. (2016). Deep learning. The MIT Press.

Hal'chyns'kyi, A. S., Heets', V. M., Kinakh, A. K., \& Semynozhenko, V. P. (2002). Innovatsiina strategiya ukrains 'kykh reform [Innovative Strategy of Ukrainian Reforms]. Kiev, Znannya Ukrainy.

Ilyich Iron and Steel Works of Mariupol. (2010). Retrieved from https://en.wikipedia.org/wiki/Illich_Steel_and_Iron_Works

Imperial College London. (2017). Stakeholder management [Powerpoint slides]. Retrieved from https://www.imperial.ac.uk/media/imperial-college/administration-and-support-services/staffdevelopment/public/impex/Stakeholder-management-21jun17.pdf

Kimmich, C., Janetschek, H., Meyer-Ohlendorf, L. et al. (2012). Methods for stakeholder analysis. Europaeischer Hochschulverlag GmbH \& Co KG, Bremen, Germany.

Lepa, R. N. (2006). Situational mechanism for training and management decisions in the enterprise: Methodology, models and methods. Donetsk, IEP NASU.

Looser, S., \& Wehrmeyer, W. (2015). Stakeholder mapping of CSR in Switzerland. Social Responsibility Journal, 11(4), 780-830. https://doi.org/10.1108/SRJ-06-2014-0071

Lusticky, M., Zaunmüllerová, P., Váchová, L., \& Kadeřábková, J. (2015). Stakeholder mapping in selected Czech regions. $16^{\text {th }}$ International Colloquium on Regional Sciences. Conference Proceedings. Valtice, 579-586.

Mabrouk, M., Sperandio, S., \& Girard, P. (2014). Stakeholder mapping in a collaborative project for a sustainable development. IFIP Advances in Information and Communication Technology (vol. 439, pp. 518-525). https://doi.org/10.1007\%2F978-3662-44736-9_63

Majumdar, S. I., Rahman, Md. S., \& Rahman, Md. M. (2014). Stakeholder prioritization in requirement engineering process: a case study on school management system. Computer Science and Engineering, 4(1), 17-27.

Martirosyan, E. G., \& Vashakmadze, T. T. (2014). SUN Cube: A new stakeholder management system for the post-merger integration process. Zagreb International Review of Economics \& Business, 17(1), 1-13. Retrieved from https://ssrn.com/abstract=2336300 
Mendelow, A. (1991). Stakeholder mapping. In Proceedings of the Second International Conference on Information Systems (pp. 407-418). Cambridge, MA, Great Britain.

Mitchell, R. K., Agle, B. R., \& Wood, D. J. (1997). Toward a theory of stakeholder identification and salience: defining the principle of who and what Really counts. Academy of Management Review, 22(4), 853-886. https://doi.org/10.5465/amr.1997.9711022105

Olson, E., Prepscius, J., \& Baddache, F. (2011). Stakeholder mapping. Business for social responsibility. Retrieved from https://www.bsr.org/reports/BSR_Stakeholder_Engagement_Stakeholder_Mapping.final.pdf

Plotitsina, L., \& Boyarov, A. (2011). The role of corporate social responsibility in the strategic management of companies focused on sustainable development. Transport Business in Russia, 9, 220-222. Retrieved from https://cyberleninka.ru/article/n/oroli-korporativnoy-sotsialnoy-otvetstvennosti-v-strategicheskom-upravlenii-kompaniyami-orientirovannymi-naustoychivoe-razvitie

Ramu, A., \& Kulkarni, S. G. (2018). Strategic identification and prioritization of stakeholders. International Journal of Pure and Applied Mathematics, 119(12), 15-21.

Szymborska, M., Domanski, R., \& Adamczak, M. (2019). Financial factors influencing the development of corporate social responsibility - study in companies operating on the polish market. In P. Golinska-Dawson \& M. Spychala (Eds.), Corporate Social Responsibility in the Manufacturing and Services Sectors (pp. 255-266). Springer Berlin Heidelberg.

Westrenius, A., \& Barnes, L. (2015). Managing complex business relationships: Small business and stakeholder salience. The Journal of Developing Areas, 49(6), 481-488. https://doi.org/10.1353/jda.2015.0104 